\title{
EDUCAÇÃO AMBIENTAL E ABELHAS: O QUE DIZEM OS LIVROS DIDÁTICOS DE BIOLOGIA?
}

\author{
Maria Mayara Vieira ${ }^{1}$ \\ Juliana do Nascimento Bendini² \\ Kairo Michel Lima Borges ${ }^{3}$
}

Resumo: Objetivou-se analisar a abordagem dos conteúdos referentes à importância das abelhas em livros didáticos de Biologia do Ensino Médio. Foram estabelecidos critérios de avaliação quanto aos assuntos considerados relevantes para o entendimento no que concerne à importância desses insetos. Dos 10 livros analisados, 8 abordaram pelo menos um dos critérios de análise. Observou-se que $60 \%$ dos livros conceituaram a polinização e $30 \%$ destacaram as abelhas como os principais polinizadores. O conteúdo "desaparecimento das abelhas" apareceu em 30\% dos livros. É preciso ampliar as discussões sobre a diversidade, importância e as consequências do desaparecimento das abelhas nos livros didáticos de biologia.

Palavras-chave: Conservação; Educação do Campo; Ecologia; Material Escolar; Polinizadores.

Abstract: This paper aimed to analyze how the content related to the importance of bees was approached in high school Biology textbooks. Evaluation criteria in relation to the subjects deemed relevant to the understanding of these insects' importance were established. 8 of the 10 textbooks analyzed approached at least one of the analysis criteria. It was noted that $60 \%$ of the textbooks conceptualized the pollinization process, and $30 \%$ highlighted the bees as the main pollinating agents. The subject "the disappearance of bees" turned up in $30 \%$ of the textbooks. Broadening the discussions on diversity, the importance and the consequences of the disappearance of bees in Biology textbooks is essential.

Keywords: Conservation; Ecology; Field Education; School Supplies; Pollinators.

${ }^{1}$ Universidade Federal do Piauí. E-mail: mayviieira1@gmail.com,

Link para o Lattes: http://lattes.cnpq.br/2472583981752634

2 Universidade Federal do Piauí E-mail: jbendini@ufpi.edu.br

Link para o Lattes: http://lattes.cnpq.br/1573600820575153

3 Universidade Federal do Piauí. E-mail: kairomichel38@gmail.com

Link para o Lattes: http://lattes.cnpq.br/0166116497126057

Revbea, São Paulo, V. 16, № 3: 404-414, 2021. 


\section{Introdução}

No Brasil, estima-se que existam mais de 2.500 espécies de abelhas, distribuídas em cinco famílias, com muitos gêneros e espécies das mais diversificadas formas, cores e tamanhos. Cada espécie exibe características próprias e desempenha um papel na natureza (SILVA et al., 2014, p. 7).

Sabe-se que cerca de $87,5 \%$ da diversidade estimada de espécies de plantas com flores dependem da polinização realizada por animais para a reprodução (OLLERTON, et al., 2011, p. 321). Entre eles, as abelhas são os mais importantes agentes, e por isso são, em grande parte, responsáveis pela manutenção da diversidade vegetal.

Ainda que a importância das abelhas seja imensurável, estes insetos estão atualmente em um acelerado processo de desaparecimento que, desde meados de 2006, vem sendo observado por meio das perdas de colônias de Apis mellifera registradas em todo o mundo, inicialmente nos Estados Unidos e na Europa (OLDROYD, 2007, p. 1195). De acordo com Pires et al. (2016, p. 422), as causas desse problema estão relacionadas principalmente aos efeitos de agrotóxicos, às deficiências nutricionais, à falta de manejo adequado e à ocorrência de patógenos e parasitas. Sobretudo os pesticidas que, de acordo com Castilhos et al. (2019, p. 263), foram apontados pelos usuários do aplicativo "Bee Alert" 4 como a principal causa das altas taxas de perdas de abelhas no Brasil.

Dessa maneira, muitas espécies correm o risco de desaparecem antes de serem conhecidas, e o enfrentamento dessa problemática pode envolver a promoção de processos de sensibilização da população acerca da conservação das abelhas, especialmente nas comunidades rurais. Estratégias educativas envolvendo crianças e adolescentes mostram-se excelentes instrumentos para promoção de processos de sensibilização, incluindo seu potencial de atingir indiretamente as famílias, pois ampliam sua percepção sobre temas atuais, como a conservação do meio ambiente e das próprias abelhas (FERREIRA et al., 2013, p. 172; TAVARES et al., 2016, p. 120).

Sá e Prato (2007, p. 109) consideram importante trabalhar, na escola, conteúdos relacionados à diversidade de abelhas e à sua importância ecológica. Os autores obtiveram resultados significativos no que se refere à sensibilização de alunos do ensino médio quanto à importância da conservação desses insetos.

Para Jaeger e Freitas $(2021$, p. 35) a escola é caracterizada como uma eficiente facilitadora para a realização de ações de sensibilização no que se refere à Educação Ambiental. E segundo Langhi e Nardi (2007, p. 87) e Miranda, Garcia e Vidotto-Magnoni (2020, p. 82), os livros didáticos consistem, na maioria das vezes, na única fonte de consulta utilizada pelos professores na

$4 \quad$ O aplicativo BeeAlert é a primeira plataforma on-line para o registro de desaparecimento ou morte massiva de abelhas em apiários, utilizando o recurso de geolocalização.

Revbea, São Paulo, V. 16, № 3: 404-414, 2021.

revista brasileira

educação ambiental 
elaboração de suas aulas teóricas e práticas e, nesse sentido, considera-se relevante que esses livros tenham enfoque nas questões ambientais, como a importância das abelhas e o declínio da população desses insetos.

Dessa maneira, o objetivo do presente trabalho foi analisar a abordagem dos conteúdos referentes à polinização, à importância das abelhas e sua organização social, à criação racional (apicultura e/ou meliponicultura), assim como o desaparecimento desses insetos, em livros didáticos de biologia do ensino médio.

\section{Material e métodos}

Foram selecionados livros didáticos de biologia do $2^{\circ}$ ano do ensino médio, visto que esses livros abordam conteúdos sobre a polinização das plantas angiospermas e são recomendados pelo Programa Nacional do Livro e do Material Didático (PNLD).

Os conteúdos referentes à polinização, à importância das abelhas, à organização social e à criação racional desses insetos, além das discussões acerca do seu desaparecimento, foram analisados em 10 livros didáticos de biologia do $2^{\circ}$ ano do ensino médio. Considerando que as discussões científicas sobre o desaparecimento das abelhas tiveram início no ano de 2006, foram analisados livros de diferentes anos de edição (após o referido marco), edições, anos letivos e editoras (Tabela 1). A pesquisa foi realizada em escolas do município de Picos, Piauí, por meio da leitura e análise do texto e de ilustrações.

Tabela 1: Lista dos livros analisados (anos de edição, edições, anos escolares e editora).

\begin{tabular}{ccccc}
\hline LIVROS (Lv) & ANO DE EDIÇÃO & EDIÇÃO & ANO & EDITORA \\
\hline Lv1 & 2016 & $3^{\text {a }}$ & $2^{\circ}$ & AJS \\
\hline Lv2 & 2016 & $3^{\text {a }}$ & $2^{\circ}$ & Saraiva \\
\hline Lv3 & 2016 & $1^{\text {a }}$ & $2^{\circ}$ & Moderna \\
\hline Lv4 & 2016 & $3^{\text {a }}$ & $2^{\circ}$ & Ática \\
\hline Lv5 & 2010 & $1^{\text {a }}$ & $2^{\circ}$ & Saraiva \\
\hline Lv6 & 2013 & $2^{\text {a }}$ & $2^{\circ}$ & AJS \\
\hline Lv7 & 2013 & $2^{\text {a }}$ & $2^{\circ}$ & Ática \\
\hline Lv8 & 2016 & $2^{\text {a }}$ & $2^{\circ}$ & Moderna \\
\hline Lv9 & 2010 & $3^{\text {a }}$ & $2^{\circ}$ & Moderna \\
\hline Lv10 & 2016 & $1^{\text {a }}$ & $2^{\circ}$ & Moderna \\
\hline
\end{tabular}

Fonte: Autoria própria.

Revbea, São Paulo, V. 16, № 3: 404-414, 2021. 
Para essa análise, foram estabelecidos critérios de avaliação dos conteúdos em relação à abordagem dos assuntos considerados importantes para entendimento quanto à importância das abelhas. Assim, foram estabelecidos os seguintes critérios: 1. Conceito e importância da polinização; 2. Destaque das abelhas como principais agentes polinizadores; 3 . Características das abelhas; 4. Organização em sociedade; 5 . Criação de abelhas; 6. Desaparecimento das abelhas; e 7. Utilização de ilustrações referentes ao conteúdo em estudo.

\section{Resultados e discussão}

A partir dos critérios determinados para a avaliação, a Figura 1 demonstra a porcentagem dos livros que abordam os conteúdos estabelecidos para a análise.

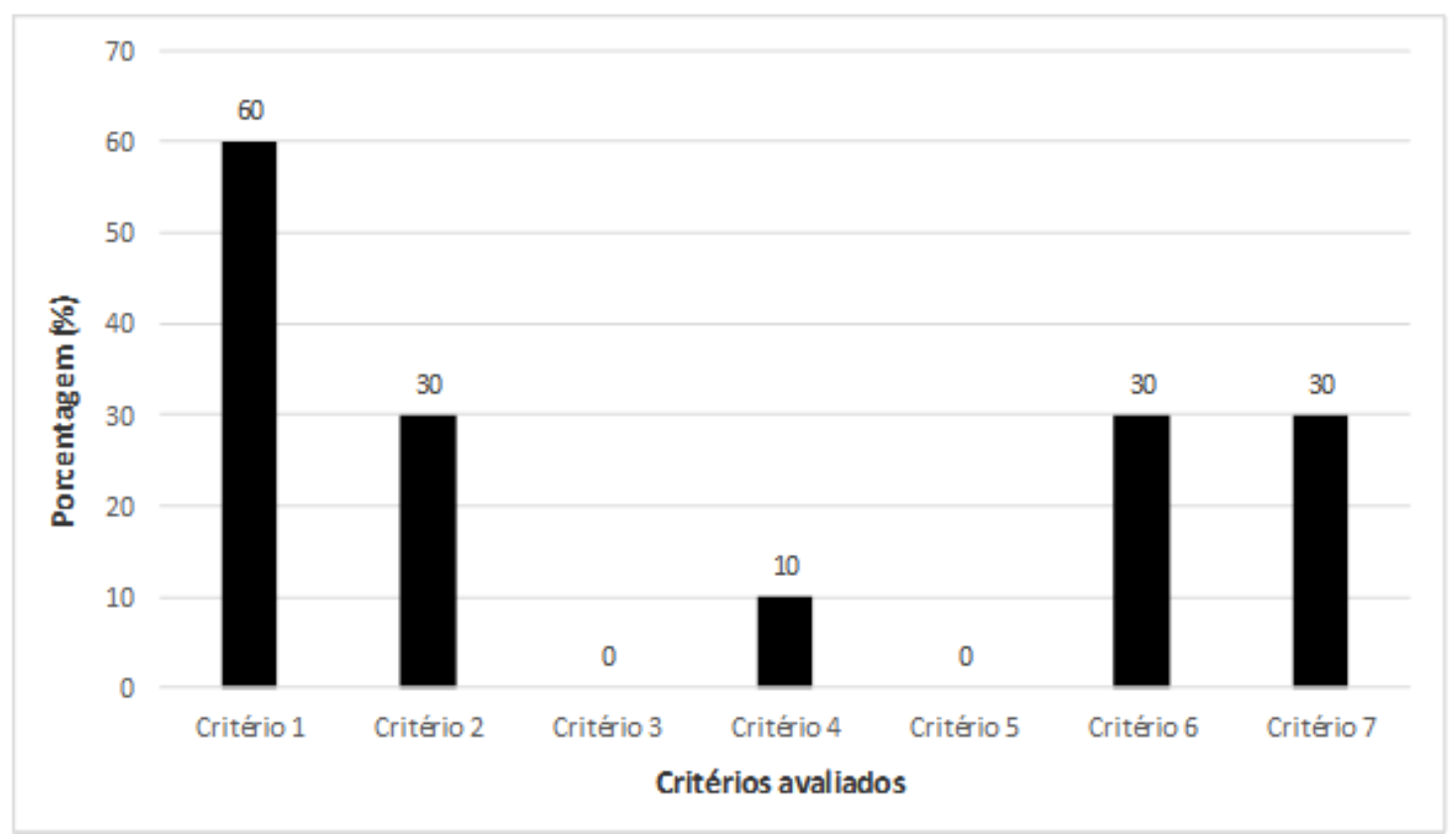

Figura 1: Percentual de livros que abordaram os critérios de análise. Critérios: 1. Conceito e importância da polinização; 2. Destaque das abelhas como principais agentes polinizadores; 3.

Características das abelhas; 4. Organização em sociedade; 5 . Criação de abelhas; 6.

Desaparecimento das abelhas; e 7. Utilização de ilustrações referentes ao conteúdo em estudo. Fonte: Autoria própria.

A partir da análise dos dados, observou-se que dois livros (Lv3 e Lv8) não atenderam a nenhum dos critérios de análise utilizados nesse trabalho. $O$ conceito e a importância da polinização foram abordados em $60 \%$ (Lv4, Lv5, Lv6, Lv7, Lv9 e Lv10) dos livros analisados. A polinização é o transporte dos grãos de pólen, armazenados no aparelho reprodutor masculino da flor, até o aparelho reprodutor feminino nas plantas superiores (COSTA; OLIVEIRA, 2013, p. 1). Segundo Yamamoto, Barbosa e Oliveira (2010, p. 176), esse processo é responsável, além da reprodução das plantas com flores, pela 
produção de alimentos e ainda pela manutenção das interações entre animais e plantas.

Diversos estudos apontam para a importância da polinização realizada por abelhas em cultivos de relevância econômica. Nesse sentido, pode-se citar os plantios de melancia (SOUZA; MALERBO-SOUZA, 2005, p. 453), de tomate (NUNES-SILVA; HRCIR; IMPERATRIZ-FONSECA, 2010, p. 140), de maracujá (VIEIRA et al., 2010, p. 52), de laranja e tangerina (NASCIMENTO et al., 2011, p. 116), de canola (ROSA; BLOCHTEIN; LIMA, 2011, p. 255), de cenoura (NASCIMENTO et al., 2012, p. 497), de morango (WITTER et al., 2012, p. 64), de acerola (OLIVEIRA; NICODEMO; OLIVEIRA, 2015, p. 64), de maçã (SHEFFIELD; NGO; AZZU, 2016, p. 12), de café (PERUZZOLO; CRUZ; RONQUI, 2019, p. 4), de framboesa (BRITO et al., 2019, p. 4), entre outros. Além desses estudos relacionados às plantas agrícolas, Kerr (1997, p. 42) sublinha a importância das abelhas, especialmente das nativas, para a polinização de $30 \%$ das espécies vegetais florestais da Caatinga e do Pantanal. O autor ressalta, ainda, que cerca de $90 \%$ das plantas florestais ocorrentes em algumas partes da Mata Atlântica e da Amazônia utilizam essas abelhas como agentes polinizadores.

Ainda sobre esse tema, somente três livros (Lv1, Lv7 e Lv10) destacaram a polinização cruzada em seu conteúdo. Vale a pena salientar que a abordagem acerca da polinização cruzada enfatiza a necessidade dos polinizadores no processo de reprodução das plantas com flores, garantindo a variabilidade genética. Em 30\% (Lv2, Lv4 e Lv7) dos livros foi atribuído destaque para as abelhas como principais agentes polinizadores. Porém, um desses livros traz essa informação somente na legenda da ilustração.

As características das abelhas não foram mencionadas em nenhum dos exemplares. Gaglianone et al. (2016, p. 172) afirmam que as abelhas possuem uma variedade de adaptações morfológicas e comportamentos especiais para a coleta de recursos florais: néctar, resinas, pólen, óleos ou perfumes. Segundo os mesmos autores, o comportamento de visita em várias flores de plantas da mesma espécie torna-se vantajoso para a formação de sementes e frutos das plantas superiores.

Em 10\% (Lv5) dos livros analisados, a organização social das abelhas da espécie Apis mellifera L. foi abordada. Em meio à grande diversidade de abelhas existentes, esses livros apresentam apenas uma espécie de abelhas como exemplo de organização social, podendo levar à constatação equivocada de que existam em nosso país exclusivamente as abelhas conhecidas como africanizadas. No trabalho de Silveira, Melo e Almeida (2002, p. 51) foram reconhecidas 1576 espécies de abelhas divididas em 207 gêneros conhecidos no Brasil. E na pesquisa de Milet-Pinheiro e Schlindwein (2008, p. 626), em uma área do agreste Pernambucano, foi possível identificar 1.004 indivíduos de abelhas pertencentes a 79 espécies, sendo elas das famílias Apidae, Halictidae, Megachilidae, Colletidae e Andrenidae. 
Entre as abelhas existem níveis de organização social diferentes. Podese destacar as abelhas que vivem em sociedade, ou seja, em uma colmeia com diferentes castas desenvolvendo funções específicas, assim como existem abelhas que têm hábitos solitários, onde somente um indivíduo realiza todas a funções necessárias para a manutenção da espécie (SILVA et al., 2014, p. 9).

Em relação às abelhas de hábitos solitários, observou-se que um dos livros (Lv1) ilustra uma abelha solitária como exemplo. De acordo com Oliveira et al. (2014, p. 8), as abelhas solitárias correspondem à maioria das espécies de abelhas existentes, porém são menos conhecidas pela população. Segundo Alves-dos-Santos (2009, p. 1), uma forma de conservar os polinizadores é preservar os locais de nidificação das abelhas, como troncos apodrecidos e barrancos, no caso de abelhas solitárias. Isso é possível a partir do conhecimento sobre a existência, diversidade e comportamento desses insetos. Nesse sentido, a falta de informações sobre as abelhas solitárias na maioria dos livros pode impactar negativamente até mesmo nas ações para a sua conservação.

A criação de abelhas não foi tratada em nenhum dos exemplares. Essa atividade é uma das mais antigas realizadas pelos humanos e, segundo Pereira et al. (2019, p. 2), a criação racional desses insetos é compatível com a conservação do meio ambiente e promove, por meio da produção e comercialização dos seus produtos e subprodutos, o desenvolvimento econômico, especialmente para os povos do campo. Segundo Melquíades e Bendini (2017, p. 32), a apicultura é uma das mais importantes atividades econômicas da região de Picos, Piaú, e faz parte da realidade de muitas famílias camponesas do semiárido piauiense. Assim, a falta de referência a essa atividade nos livros didáticos pode ser um fator de desvalorização da apicultura e pode reforçar, nesse sentido, a falta de interesse dos jovens por esta prática, o que vem sendo relatado pelos apicultores da região de Picos.

A problemática do desaparecimento das abelhas foi encontrada, em forma de discussão, em apenas três livros analisados (Lv1, Lv2 e Lv10). Os autores dos livros Lv1 e Lv10 fazem um alerta sobre o declínio das populações de abelhas e enfatizam que o uso de pesticidas está entre os principais fatores para sua ocorrência. Os autores do livro Lv2 utilizam as informações da campanha "Bee or not to be" 5 como maneira de divulgação sobre o declínio de populações de abelhas em várias partes no mundo, inclusive no Brasil, e discorrem sobre como esse problema pode afetar a produção de alimentos, dando destaque para a abelha como principal polinizador.

Segundo Potts et al. (2010, p. 345), o declínio dessa população de insetos resultará na queda significativa do serviço de polinização, ocasionando uma grande perda da biodiversidade e grandes impactos ambientais e

55 Campanha em proteção das abelhas de autoria da Organização não Governamental "Bee or not to be". 
econômicos no mundo. Para Potts et al. (2016, p. 16), cerca de $90 \%$ da produção de plantas cultivadas decairia caso a polinização animal cessasse.

Os estudos de (KLEIN et al., 2006, p. 303; OLIVEIRA, 2015, p. 4; CAIRES; BARCELOS, 2017, p. 4; MARTIN-CULMA; ARENAS-SUÁRES, 2018, p. 238; BERINGER, et al., 2019, p. 17, BERNADES; MARQUES; LIMA, 2019, p. 77) apontam para o declínio populacional desses polinizadores. Os autores afirmam que esse declínio é causado por diversos fatores, em sua maioria pelo uso de agrotóxicos. Embora Paixão e Silva (2021, p. 1) tenham investigado a importância da poluição ambiental atmosférica no declínio das populações de abelhas, em revisão bibliográfica realizada não observaram estudos que confirmassem a influência direta de óxidos de nitrogênio e de seus impactos nas populações desses insetos.

$O$ fato de apenas três dos livros analisados abordarem 0 desaparecimento das abelhas revela que, possivelmente, os estudantes terminem sua formação educacional básica com poucas informações sobre esse assunto. Pinto et al. (2018, p. 161) observaram que os livros didáticos utilizados em uma escola pública localizada na zona rural de Cárceres, Mato Grosso, não abordavam claramente o papel das abelhas na manutenção da biodiversidade, assim como as causas e consequências do colapso de suas populações. Os autores realizaram, ainda, ações de sensibilização referentes ao tema na referida escola e verificaram que as atividades de Educação Ambiental contribuíram na complementação do conteúdo do livro didático sobre as abelhas e na construção da percepção ambiental crítica dos educandos sobre a importância das abelhas para a biodiversidade.

Christofori e Farias (2019, p. 54) observaram, entre alunos do Ensino Médio no município de Aquidauana, Mato Grosso do Sul, dificuldades de relacionar temas cotidianos com a polinização, e que as informações adquiridas sobre o processo são, em sua maioria, obtidas por meio da internet e redes sociais.

Tavares et al. (2016, p. 15), analisando a abordagem dos conteúdos referentes às abelhas e à polinização em livros didáticos de ciências do sétimo ano do Ensino Fundamental, observaram que os livros apresentaram pelo menos algum conceito incompleto e incoerências, tanto nas informações, quanto nas ilustrações. No que se refere às ilustrações, é importante ressaltar que, no presente estudo, gravuras referentes à temática apareceram em $30 \%$ dos livros (Lv1, Lv4 e Lv10). Para Martins, Gouvêa e Piccinini (2005, p. 38), é de grande valia a utilização de imagens nos livros didáticos, uma vez que tal prática possibilita aos alunos uma visão semiestruturada do conceito e ideias científicas.

No Brasil, o livro didático é amplamente difundido como uma ferramenta para o ensino a ser utilizada pelos professores. Segundo Tagliani (2011, p. 137), é um material comum nas escolas e resume-se a um objeto que auxilia os docentes no processo de ensino/aprendizagem. $\mathrm{O}$ autor ainda cita que 0 livro é uma ferramenta norteadora aos alunos nas escolas e até mesmo nas 
suas casas, posto que, em alguns casos, têm o livro como único recurso para pesquisa.

Diante das fragilidades observadas no presente estudo, no que se refere aos conteúdos relacionados às discussões acerca da diversidade, importância e conservação das abelhas, Souza e Garcia (2019, p. 128) indicam que os professores não devem ficar atrelados somente ao que esse instrumento pedagógico explora. Os autores recomendam que os professores estejam atentos às finalidades do Ensino de Ciências para a formação da alfabetização científica dos estudantes.

\section{Conclusões}

Do total de 10 livros analisados, 8 abordaram pelo menos um dos critérios de análise. Observou-se que a maioria dos livros (60\%) conceituou e expôs razoavelmente o processo de polinização, já que não foi explorado o conceito de polinização cruzada. Apenas 30\% do material analisado destacou as abelhas como os principais polinizadores.

O critério referente às características e à criação das abelhas não foi abordado em nenhum dos exemplares. A temática relacionada ao desaparecimento das abelhas apareceu em apenas 30\% dos livros, e apenas $10 \%$ dos livros referiu-se sobre a organização social das abelhas e apresentou uma espécie de abelha como exemplo, a abelha Apis mellifera.

Ao final dessa análise, constatou-se que é preciso melhorar a abordagem dos conteúdos referentes às abelhas e ampliar as discussões sobre o desaparecimento desses polinizadores nos livros de biologia. Com isso, é importante que os professores avaliem bem os livros que serão utilizados nas escolas, visando 0 incremento desses conteúdos e a sensibilização dos alunos em relação a essa problemática e, por meio de tais ações, torná-los agentes de mudança a favor da conservação das abelhas.

\section{Referências}

ALVES-DOS-SANTOS, I. Por que preservar troncos apodrecidos e barrancos em sua propriedade? Mensagem Doce, São Paulo, n. 100, março 2009. Disponível em: <http://www.apacame.org.br/mensagemdoce/100/artigo.htm>. Acesso em: 22 ago. 2020.

BERINGER, J.; MAIEL, F. L.; TRAMONTINA, F. F. O declínio populacional das abelhas: causas, potenciais soluções e perspectivas futuras. Revista Eletrônica Científica da UERGS, v. 5, n. 1, p. 17-26, 2019.

BERNARDES, R. C.; MARQUES, R. D.; LIMA, M. A. P. Declínio de abelhas silvestres e agroecologia. In: CARMO, D. L.; PEREIRA, D. S.; MIGUEL, E. S.; LOPES, S. O.; PRIORE, S. E... et al. Pesquisa em Agroecologia: conquistas e perspectivas. Viçosa, MG: Furnabe, 2019. 
BRITO, T. D. A. et al. A cultura da framboesa. Presença de néctar nas flores e sua extração pelas abelhas. Voz do Campo-Agrociência, v. 222, p. 3-4, 2019.

CAIRES, S. C.; BARCELOS, D. Colapso das abelhas: Possíveis causas e consequências do seu desaparecimento na natureza. Acta Apicola Brasilica, v. 5, n. 1, p.11-15, 2017.

CASTILHOS, D.; BERGAMO, G. C.; GRAMACHO, K. P.; GONÇALVES, L. S. Bee colony losses in Brazil: a 5-year online survey. Apidologie, v. 50, p. 263272, 2019.

COSTA, C. C.; DE OLIVEIRA, F. L. Polinização: serviços ecossistêmicos e o seu uso na agricultura. Revista Verde de Agroecologia e Desenvolvimento Sustentável, v. 8, n. 3, p. 1-10, 2013.

CHRISTOFORI, A. Á. M.; FARIA, R. R. Percepção sobre a crise global dos polinizadores por alunos do Ensino Médio de Aquidauana/MS. Revista Pantaneira, v. 16, p. 43-56, 2019.

FERREIRA, E. A. et al. Meliponicultura como ferramenta de aprendizado em Educação Ambiental. Ensino, Saúde e Ambiente, v. 6, n. 3, p. 162-174, 2013.

FREITAS, P. V. D. X. et al. Declínio populacional das abelhas polinizadoras: Revisão. PUBVET, v. 11, p. 1-102.

GAGLIANONE, M. C. et al. Polinizadores e os serviços Ambientais: uma Abordagem extensionista Voltada à Conservação. Revista de Extensão UENF, v. 2, n. 1, p. 172, 2016.

JAEGER, A. P.; FREITAS, E. M. Práticas de Educação Ambiental: percepção de professores de ensino fundamental de escolas públicas municipais do Rio Grande do Sul. Revista Brasileira de Educação Ambiental, v. 16, n. 1, p. 2334, 2021.

KERR, W. E. A importância da meliponicultura para o país. Revista Biotecnologia Ciência \& Desenvolvimento, v. 1, n. 3, p. 42-44, 1997.

KLEIN, A. M. et al. Importance of pollinators in changing landscapes for world crops. Proceedings of the royal society B: biological sciences, n. 274 , v. 1608, p. 303-313, 2006.

LANGHI, R.; NARDI, R. Ensino de astronomia: erros conceituais mais comuns presentes em livros didáticos de ciências. Caderno Brasileiro de Ensino de Física, v. 24, n. 1, p. 87-111, 2007.

MARTIN-CULMA, N.Y.; ARENAS-SUÁREZ, N.E. Daño colateral en abejas por la exposición a pesticidas de uso agrícola. Entramado, v. 14, n. 1, p. 232-240, 2018.

MARTINS, I.; GOUVÊA, G.; PICCININI, C. Aprendendo com imagens. Ciência e Cultura, v. 57, n. 4, p. 38-40, 2005.

MELQUÍADES, C. C. V.; BENDINI, J. N. Apicultura no semiárido piauiense: perspectivas e desafios. In: G.A. Arrais, \& J.N. Bendini (Orgs.). Pesquisas e ações do grupo de estudos sobre abelhas do semiárido piauiense. Teresina: EDUFPI, 2017. 
MILET-PINHEIRO, P.; SCHLINDWEIN, C. Comunidade de abelhas (Hymenoptera, Apoidea) e plantas em uma área do Agreste pernambucano, Brasil. Revista Brasileira de Entomologia, v. 52, n. 4, p. 625-636, 2008.

MIRANDA, C. B.; GARCIA, D. A. Z.; VIDOTTO-MAGNONI, A. P. Os vertebrados brasileiros em livros didáticos de biologia. Revista Brasileira de Educação Ambiental, v. 15, n. 7, p. 71-85, 2020.

NASCIMENTO, E. T. D. et al. Diversidade de abelhas visitantes das flores de Citrus em pomares de laranjeira e tangerineira. Revista Brasileira de Fruticultura, v. 33, n. 1, p. 111-117, 2011.

NASCIMENTO, W. M. et al. Utilização de agentes polinizadores na produção de sementes de cenoura e pimenta doce em cultivo protegido. Horticultura Brasileira, v. 30, n. 3, p. 494-498, 2012.

NUNES-SILVA, P. N.; HRNCIR, M.; IMPERATRIZ-FONSECA, V. L. I. A polinização por vibração. Oecologia Australis, v. 14, n. 1, p. 140-151, 2010.

OLDROYD, B. P. What's killing American honeybees? PLoS Biol., v. 5, n. 6, e168, p. 1195-1199, 2007.

OLIVEIRA, J. E. M.; NICODEMO, D.; DE OLIVEIRA, F. F. Contribuição da polinização entomófila para a produção de frutos de aceroleira. Pesquisa Agropecuária Tropical, v. 45, n. 1, p. 56-65, 2015.

OLIVEIRA, M. O. Declínio populacional das abelhas polinizadoras de culturas agrícolas. Acta Apicola Brasilica, v. 3, n. 2, p. 01-06, 2015.

OLIVEIRA, R. et al. Abelhas solitárias produzem acerolas. Rio de Janeiro: Funbio, 2014.

OLLERTON, J; WINFREE, R.; TARRANT, S. How Many Flowering Plants are Pollinated by Animals? Oikos, v. 120, n. 3, p. 321-326, 2011.

PAIXÃO, G. P. G.; SILVA, C. M. IMPACTOS DA POLUIÇÃO ATMOSFÉRICA NO PROCESSO DE POLINIZAÇÃO DAS ABELHAS. Revista lberoAmericana de Ciências Ambientais, v. 12, n. 3, 2021.

PEREIRA, K. R. B. et al. Apicultura Didática: Um Relato de Experiência sobre a Vivência em Agroecologia no Apiário da UFRB. Revista Craibeiras de Agroecologia, v. 4, Supl., e9001, p.1-6, 2019.

PERUZZOLO, M. C.; CRUZ, B. C. F.; RONQUI, L. Polinização e produtividade do café no Brasil. PUBVET, v. 13, n. 4, p. 1-6, 2019.

PINTO, C. L.; BAMPI, A. C.; GALBIATI, C. Importância das abelhas para a biodiversidade na percepção de educandos de Cáceres, MT. Revista IberoAmericana de Ciências Ambientais, v. 9, n. 1, p. 152-163, 2018.

PIRES, C. S. S. et al. Enfraquecimento e perda de colônias de abelhas no Brasil: há casos de CCD? Pesquisa Agropecuária Brasileira, v. 51. n. 5, p. 422-442, 2016.

POTTS, S. G. et al. Global pollinator declines: trends, impacts and drivers. Tendências em ecologia e evolução, v. 25, n. 6, p. 345-353, 2010.

revista brasileira educação ambiental 
POTTS, S. G. et al. 0 relatório de avaliação da Plataforma Intergovernamental de Política Científica sobre Biodiversidade e Serviços Ecossistêmicos sobre polinizadores, polinização e produção de alimentos. Bonn: Secretariado da Plataforma Intergovernamental de Política Científica emBiodiversidade e Serviços de Ecossistemas, 2016.

ROSA, A. S.; BLOCHTEIN, B.; LIMA, D. K. Honey bee contribution to canola pollination in Southern Brazil. Scientia Agricola. v. 68, n. 2, p. 255-259. 2011.

SÁ, N. P.; PRATO, M. Conhecendo as abelhas: Um projeto de ensino. Bioscience Journal, v. 23, p. 107-110, 2007.

SHEFFIELD, C.; NGO, H. T.; AZZU, N. Um manual sobre polinização de maçã. Roma: Organização das Nações Unidas para Agricultura e Alimentação (FAO), 2016.

SILVA, C. I. et al. Guia ilustrado de abelhas polinizadoras no Brasil. 1. Ed. São Paulo: Instituto Avançado da Universidade de São Paulo, Co-editor: Ministério do Meio Ambiente-Brasil. 2014.

SILVEIRA, F. A.; MELO, G. A.; ALMEIDA, E. A. Abelhas brasileiras: sistemática e identificação. 1 ${ }^{a}$ ed. Belo Horizonte: PROBIO - PNUD, 2002.

SOUZA, C.L.P.; GARCIA, R.N. Uma análise do conteúdo de Botânica sob o enfoque Ciência-Tecnologia-Sociedade (CTS) em livros didáticos de Biologia do Ensino Médio. Ciência \& Educação (Bauru), v. 25, n. 1, p. 111-130, 2019.

SOUZA, F. F.; MALERBO-SOUZA, D. T. Entomofauna visitante e produção de frutos em melancia (Citrullus lanatus Thunb.) - Cucurbitaceae. Acta Scientiarum Agronomy, v. 27, n. 3, p. 449-454, 2005.

TAGLIANI, D. C. O livro didático como instrumento mediador no processo de ensinoaprendizagem de língua portuguesa: a produção de textos. Revista Brasileira de Linguística Aplicada, v. 11, n. 1, p. 135-148, 2011.

TAVARES, M. G. et al. Abelhas sem ferrão: Educação para Conservação Interação Ensino-Pesquisa-Extensão voltada para o Ensino Fundamental. Revista Brasileira de Extensão Universitária, v. 7, n. 2, p. 113-120, 2016.

VIEIRA, P. F. S. P. et al. Valor econômico da polinização por abelhas mamangavas no cultivo do maracujá-amarelo. Revista iberoamericana de economía ecológica, v. 15, p. 43-53, 2010.

WITTER, S. et al. Desempenho de cultivares de morango submetidas a diferentes tipos de polinização em cultivo protegido. Pesquisa agropecuária brasileira, Brasília, v. 47, n. 1, p. 58-65, 2012.

YAMAMOTO, M.; BARBOSA, A. A. A.; OLIVEIRA P. E. A. M. A polinização em cultivos agrícolas e a conservação das áreas naturais: o caso do maracujáamarelo (Passiflora edulis f. flavicarpa Deneger). Oecologia Australis, v. 14, n. 1, p. 174-192, 2010. 